\title{
Desconcerto na clínica : erotismo na transferência e na contratransferência ${ }^{1}$
}

\author{
Sandra Lorenzon Schaffa ${ }^{2}$
}

Eu cantarei de amor tão docemente / Por uns termos em si tão concertados, / Que dois mil acidentes namorados / Faça sentir ao peito que não sente. L. Camões

Au commencement de l'expérience analytique était l'amour. J. Lacan

No começo era o amor. O momento histórico onde do encontro de um homem e uma mulher, Joseph Breuer e Anna O, nasceu a psicanálise, batizada então por Anna $\mathrm{O}$ de talking cure, é evocado por J. Lacan na introdução de seu Seminário sobre $A$ Transferência. Joseph Breuer retrocedeu, mas Sigmund Freud seguiu adiante com seu desejo de investigar a natureza do envolvimento entre os protagonistas da aventura psicanalítica como os Estudos sobre a Histeria testemunham.

Foi outra mulher, Dora, que ofereceu a Freud a figuração mais surpreendente desse envolvimento como contágio entre cenas psíquicas, do momento em que subitamente dispara o alarme de incêndio durante uma representação teatral ${ }^{3}$.

Escrito em 1914, sob o impacto da eclosão da guerra, "Observações sobre o amor transferencial" cria o neologismo Übertragungsliebe que acola transferência (Übertragung) e amor (Liebe). ${ }^{4}$

Uma nota dos editores da edição das Obras Incompletas, assinala que a partir deste artigo duas vias se abrem para a posteridade. "De um lado, os textos sobre a contratransferência, que marcaram época entre os pós-freudianos, especialmente entre os membros da escola kleiniana, com destaque para o pioneiro ensaio de Paula Heimann (1950); de outro lado, as elaborações de Lacan e sua escola acerca do desejo do analista (1958)." (Heliodoro, F. e Iannini, G., 2016, p.181).

\footnotetext{
${ }^{1}$ Este trabalho foi apresentado na mesa " Desconcertos em análise : o erotismo na trasnferência e na contratransferencia" com José Martins Canelas Neto no I Simpósio Bienal "O mesmo, o outro: Psicanálise em movimento" da Sociedade Brasileira de Psicanálise de São Paulo.

2 Analista Didata e docente da Sociedade Brasileira de Psicanálise de São Paulo.

${ }^{3}$ Freud (1905 (1901)), Análise fragmentária de um caso uma Histeria, "O Caso Dora".

$4 \quad$ Bemerkungen über die Übertragungsliebe (Weitere Ratschläge zur Technik Psychoanalyse), as edições posteriores a 1918 omitiram o subtítulo do artigo que Freud considerava o mais útil dessa série de artigos técnicos como notam os editores das Obras Incompletas de Sigmund Freud, Pedro Heliodoro Tavares e Gilson Iannini.
} 
O tratamento de Maria remonta ao inicio da minha formação. Experiência perturbadora de descoberta da transferência sob a forma de uma exigência impetuosa de amor no encontro analítico.

"O psicanalista sabe que trabalha com as forças mais explosivas e que são necessárias cautela e meticulosidade, assim como no caso dos químicos. Mas quando é que a um químico foi interditado se ocupar com materiais explosivos, indispensáveis, por sua periculosidade, apesar de seu efeito? (...) Certamente não sou favorável a que se abdique dos métodos de tratamento inofensivos. Para alguns casos eles são suficientes, e, de resto a sociedade humana não precisa nem do furor sanandi nem de qualquer outro tipo de fanatismo, mas significaria subestimar e muito as psiconeuroses segundo as suas origens e sua importância prática se acreditarmos que essas afecções possam ser derrotadas através de operações com meios diminutos e inofensivos." (S. Freud, 2017, p.180).

Desde o inicio do tratamento, Maria é invadida por sentimentos amorosos e eróticos pela analista. Esses transbordamentos criavam situações difíceis e ameaçavam a continuidade da análise. A demanda de uma correspondência amorosa sem falhas impunha-se como um fio de navalha a ser enfrentado.

Freud deu estatuto de resistência a essa moção amorosa, no entanto, acentuou a necessidade de não afugentá-la :

"Acatar as demandas de amor por parte da paciente é tão fatal para análise quanto a repressão [Unterdrückung] delas. O caminho do analista é outro para o qual a vida real não oferece modelo. Evitamos desviar da transferência amorosa, afugentá-la ou estragá-la na paciente; também nos abstemos ferrenhamente de toda correspondência desse amor. Mantemos a transferência amorosa , a tratamos como algo irreal, como uma situação que deva ser enfrentada no tratamento e reconduzida às suas origens inconscientes (...)" (Freud, 2017, p.173-4)

O tema proposto, "Desconcerto na clínica : erotismo na transferência e na contratransferência" convoca o significante "desconcerto". Evoca sem dúvida o poeta que cantou o amor como desconcerto do mundo. Esse significante ainda, tentadoramente, convida ao jogo de palavras : "desconcerto" ou "desconserto"? Se fosse desconserto, remeteria ao que Freud condenou de modo explícito : o desconserto deve ser evitado, tratemos de não estragar a moção amorosa que queima na transferência.

Quanto a "desconcerto", pensaríamos que envia a duas direções, em primeiro lugar ao transtorno experimentado pelo analista (contratransferência), em segundo, à desordem temporal entre as cenas (transferência) que o diálogo comporta; neste último sentido implica nada menos que a exigência crucial da análise, de seu método.

Em termos freudianos, a irrealidade do amor de transferência reside em sua condição inatual, trata-se não de um amor criado pela resistência pois a resistência o encontra instalado, a resistência explora e agrava suas manifestações. Esse amor, escreve Freud, 
"Não traz um único traço novo, oriundo da situação presente, mas é composto integralmente de repetições e retomadas de reações antigas até mesmo infantis." (Freud, 1917, p. 175)

No seio da transferência amorosa, um fundo de desolação depressiva, é possível escutar no apelo de correspondência incondicional seu caráter de urgência de um outro que corresponda a uma presença sem falhas, Maria é levada a formular a pergunta que insistiria em todo curso desse tratamento.

"Porque é tão difícil manter a sua presença ?"

A questão da presença da analista foi o eixo crucial dessa análise.

A transferência amorosa pode ser reconhecida como uma falha na constituição do maternal. Na demanda imperativa de uma presença asseguradora, o apelo a um maternal, designado pela situação de desamparo, remete a um tempo de indistinção sujeito-objeto.

A demanda incoercível de presença na análise de Maria, sua necessidade imperiosa do outro na transferência, levou-me à tese de Patrick Merot (2014 [2010]) no seu Relatório ao Congrès des Psychanalystes de Langue Française , CPLF, sobre o maternal. O autor encontra no Projeto de 1895 a formulação princeps do momento da ação específica como fundador do narcisismo primário constitutivo do sujeito, na sua relação com o outro, no horizonte da experiência de apaziguamento e desamparo. O socorro, tornado pela repetição experiência de satisfação, constitui no après-coup o outro maternante enquanto mãe.

Esta via permite penetrar o solo transferencial de onde brota a demanda incoercível de presença de Maria. No infante freudiano, o estado crucial de dependência do outro por conta de sua imaturidade inicial o faz incapaz de realizar a ação específica, única saída para os transbordamentos de excitação que o assaltam.

"Quando a pessoa que oferece sua ajuda efetuou, no mundo exterior, para a pessoa em desamparo, o trabalho da ação específica, essa última está em condições, através de dispositivos reflexos, de realizar diretamente, no interior de seu corpo, a operação necessária à supressão do estímulo endógeno. O conjunto constitui então uma experiência vivida de satisfação, que tem consequências as mais decisivas para o desenvolvimento funcional da pessoa." Freud (2006, p. 626).

O desamparo está justamente no centro do sofrimento de Maria. A natureza passional da transferência testemunha a busca de uma união com um outro - mesmo (numa conjunção constituinte da experiência vivida de satisfação da ação especifica) para sempre aí. Sob a dimensão erótica da transferência, uma necessidade narcísica primária nutre-se da sexualização das relações. Não é demais sublinhar que a constituição narcísica primordial implica uma troca amorosa entre dois corpos tal que possa favorecer uma estruturação do autoerotismo da criança, sem o que ela ficará entregue sem defesas a forças pulsionais invasivas.

O desafio contra-transferencial reside na dificuldade de sustentar a ambiguidade no interior dessa demanda narcísica fortemente sexualizada. A demanda erótica que é 
demanda de alucinação, arcaica, inatual, exige de modo crucial a modulação da qualidade libidinal da presença do analista. Todo excesso pode ter por efeito a destruição das possibilidades auto-eróticas que sustentam a vida psíquica. Segundo Pierre Fédida (1991, p.149-170), trata-se de assegurar esse outro do auto, um outro não personificado e não representável, que como interlocutor interno da fala analítica se tornará o "suporte da ilusão de amor". O que chama outro aponta para Eros presente na fala, sem o que não restará senão uma pulsionalidade autística.

A abordagem de Pierre Fedida leva em conta exigências intrínsecas à metapsicologia. P. Fédida atribui um valor essencialmente crítico à contratransferência ${ }^{5}$. O erro técnico de Freud no manejo do caso Dora ilustra-se enquanto falsa conexão ao colocar o analista em pessoa como destinatário da palavra intensamente despertada no tratamento. $\mathrm{O}$ valor de crise, ou de processo crítico, da contratransferência é o de sinalizar o lugar de emergência do traumático da sexualidade.

Responder a essa injunção técnica paradoxal de acolhimento da demanda amorosa sem satisfazê-la exige do analista a busca uma "justa distância entre os corpos se dispondo no lugar que convém à cada um em sua própria cena." Fédida, (1992, p. 156). Distância graças à qual a palavra pode encontrar seu poder de traduzir, transportar, transferir, sem que os corpos nem as memórias se confundam.

A ideia de contratransferência como crise leva a reconhecer na demanda amorosa a necessidade imperativa de constituição da ilusão especular de um duplo imaginário protético. Um excesso de excitações teria tornado impossível, na relação precoce com o seio materno, desenvolver a capacidade de simbolizar o objeto em sua ausência, era o que a análise de Maria fazia pensar.

Em meio a movimentos transferenciais complexos, os sonhos da analisanda constroem paisagens geladas e campos ameaçados de incêndios, criam uma analista mãe sedutora que é também quem poderá transformar o fogo devastador em calor narcisante. A fórmula ferencziana da paixão e da ternura ganha no horizonte dessa análise uma dimensão dramática até que o amor de transferência se pudesse tornar um pilar restaurador do narcisismo primário.

\footnotetext{
5 “A teorização da contratransferência se desenvolveu (...) como uma teoria fenomenológica da intersubjetividade da técnica comportando uma verdadeira função cognitiva pragmática do afeto do analista no tratamento. Os mecanismos da "identificação projetiva" em obra nas transferências do paciente seriam operadores desse conhecimento contra-transferencial pelo analista não somente dos afetos que vem a experimentar e nomear em si mesmo mas atos de cognição por esses afetos de modos de comunicação primitiva que o paciente reproduziria na pessoa do analista.” Fédida, 1992, p.11/ 12.
} 
Freud viu na contratransferência principalmente um obstáculo ${ }^{6}$, mas se interessou pelo "instrumento" do qual dispõe o inconsciente de cada um para interpretar as expressões do inconsciente nos outros. Lacan, por sua vez, considerou que o termo contratransferência não convém para designar a especificidade da função do analista. Ao comentar os relatos de experiências contra-transferenciais de analistas como Paula Heimann, M. Little, Lucia Tower, vê nesse "contra" algo que se apoia na compreensão: a compreensão é algo de que o analista se deve descolar.

Para Lacan, o analista "deve sempre por pôr em dúvida o que ele compreende, dizerse que o que procura atingir é o que não compreende. É somente na medida em que, decerto, ele sabe o que é o desejo, mas não sabe o que esse sujeito, com quem embarcou na aventura analítica, deseja, que ele está em posição de ter em si, deste desejo, o objeto". (Lacan, 1991, p234).

O amor transferencial descobre a condição técnica essencial da clínica, desconforto na clínica, diríamos, na condição de pensar tratar-se de desconforto fundamental pois que não se subordina à inteligência da intersubjetividade - o caminho do analista é outro para o qual a vida real não oferece modelo - mas decorre de uma disparidade irredutível entre os sujeitos, tempos e cenas psíquicas a que o diálogo analítico dá vida. $^{7}$

\section{Referências}

Heliodoro, F. e Iannini, G. (2016), Obras Incompletas de Sigmund Freud, 6, Fundamentos da Clínica Psicanálítica, Ed. Autêntica, Belo Horizonte.

Fédida, P. (1991) Auto-erotismo e autismo : condições de eficácia de um paradigma em psicopatologia, Nome, figura e memoria. A linguagem na situação psicanalítica, São Paulo, Editora Escuta.

Fédida, P. (1992) Crise et contre-transfert, Paris, PUF.

Freud, S. (2017), Obras Incompletas de Sigmund Freud, , Belo Horizonte, Ed. Autêntica. (trabalho original publicado em 1915[1914])

S. Freud (2017), Obras Incompletas de Sigmund Freud, Ed. Autêntica Belo Horizonte.

S. Freud (2017), Obras Incompletas de Sigmund Freud, Ed. Autêntica Belo Horizonte, p.180)

\footnotetext{
${ }^{6}$ A primeira menção ao fenômeno da contratransferência teria sido feita numa carta a Jung de 7 de junho de 1909 a propósito do tratamento de Sabina Spielrein. Cf. nota tradutor das obras incompletas, Fundamentos da clínica psicanalítica, (2016, p.181).

7 "Tratarei da transferência em sua disparidade subjetiva, sua pretensa situação suas excursões técnicas". Disparidade (...) "sublinha essencialmente que isso de que se trata vai mais longe que a simples noção de dissimetria entre sujeitos. Ela se insurge, desde o princípio, contra a ideia de que a intersubjetividade possa por si só, oferecer o quadro no qual se inscreve o fenômeno." (Lacan 1991, p.11) .
} 
Freud, S. (2006), Projet d'une Psychologie, Lettres à Wilhelm Fliess, Paris, PUF. (trabalho original publicado em 1895).

Lacan J. (1991), Seminaire, Livre VIII, Le transfert, Paris, Du Seuil (aula de 8 de março de 1961).

Merot, P. (2014) Dieu la mère. Trace du maternal dans le religieux, Paris, PUF. (trabalho original: Trace du maternal dans le religieux, Bulletin de la Societé Psychanalytique de Paris, Paris, PUF, 2010). 